NBER WORKING PAPER SERIES

\title{
DISTRIBUTIONAL DISPUTES AND CIVIL CONFLICT
}

\author{
Herschel I Grossman \\ Working Paper 9794 \\ http://www.nber.org/papers/w9794 \\ NATIONAL BUREAU OF ECONOMIC RESEARCH \\ 1050 Massachusetts Avenue \\ Cambridge, MA 02138 \\ June 2003
}

The views expressed herein are those of the authors and not necessarily those of the National Bureau of Economic Research.

(C2003 by Herschel I. Grossman. All rights reserved. Short sections of text not to exceed two paragraphs, may be quoted without explicit permission provided that full credit including $(\mathbb{C}$ notice, is given to the source. 
Distributional Disputes and Civil Conflict

Herschel I. Grossman

NBER Working Paper No. 9794

June 2003

JEL No. D74

\begin{abstract}
Some polities are able to use constitutionally prescribed political processes to settle distributional disputes, whereas in other polities distributional disputes result in civil conflict. Theoretical analysis reveals that the following properties help to make it possible to design a self-enforcing constitution that can settle recurring distributional disputes between social classes without civil conflict:

- Neither social class has a big advantage in civil conflict.

- The expected incremental costs of civil conflict are large relative to aggregate appropriable economic rents.

- Both social classes are greatly concerned about the future consequences of their current actions.

Theoretical analysis also reveals that a self-enforcing constitution can require limitations on the prerogatives of winners of constitutional contests such that on average the distribution of appropriable economic rents under the constitution is not too favorable to one social class or the other and such that the outcome of a constitutional contest does not matter too much for the current distribution of economic rents.
\end{abstract}

\author{
Herschel I. Grossman \\ Department of Economics \\ Box B \\ Brown University \\ Providence, RI 02912 \\ and NBER \\ herschel_grossman@brown.edu
}


Distributional disputes between social classes are ubiquitous. Some polities are able to use constitutionally prescribed political processes to settle these disputes, whereas in other polities distributional disputes between social classes result in civil conflict. Why do constitutionally prescribed political processes sometimes succeed but other times fail to prevent civil conflict?

The political process prescribed by a constitution includes two essential components: the nature of constitutional contests and the prerogatives of winners of these constitutional contests. ${ }^{1}$ Because the constituent groups of a polity cannot make binding commitments to abide by a constitution, a constitutionally prescribed political process provides a viable alternative to civil conflict only if the parties to a distributional dispute voluntarily choose to accept the outcome of this political process - that is, only if the constitution is self enforcing.

This paper presents a theoretical analyses of the possibility of designing a self-enforcing constitution that can settle recurring distributional disputes between social classes. The analysis is concerned with discovering the configurations of exogenous parameters under which the set of self-enforcing constitutions is not empty. The relevant exogenous parameters include the probabilities associated with the distributional consequences of civil conflicts, the expected incremental costs of civil conflicts, the size of aggregate appropriable economic rents, and the amount of concern for the future consequences of current actions. ${ }^{2}$

\footnotetext{
${ }^{1}$ These components can be the subject of the constitution, or they can be derived from general principles expressed in the constitution. In addition, these components, or the general principles from which they are derived, can be embodied either in explicit provisions of the constitution or in implicit understandings. Actual constitutionally prescribed political processes also vary widely. In electoral democracies constitutional contests involve periodic competition for the votes of an electorate. In contrast, in aristocracies constitutional contests involve competition for the favor of wise men, elders, or hereditary rulers. Many constitutions combine democratic and aristocratic features.

${ }^{2}$ The present paper is not concerned with the process of creating a constitution. Specifically, the paper does not address the question of which constitution would be chosen from the set of self-enforcing constitu-
} 


\section{A Simple Constitution}

Assume that two social classes have to settle a recurring distributional dispute over aggregate appropriable economic rents. ${ }^{3}$ Let $L$, for landlords or capitalists, and $W$, for workers, denote the social classes. ${ }^{4}$ Also, let $y$ denote aggregate appropriable economic rents, and let $s, s \in[0,1]$, denote the share of $y$ that $L$ receives, where $W$ receives the share, $1-s$.

Consider initially a simple constitution that prescribes a periodical constitutional contest to determine which social class has the prerogative to choose $s$, but that places no limits on the prerogatives of the winner in choosing $s$. Let $L$ have probability $p$, and let $W$ have probability $1-p$, of winning each constitutional contest. These probabilities depend on many factors, including the nature of constitutional contests, the cohesiveness of the social classes, and the salience of issues other than the distribution of economic rents. Assume that $p$ is common knowledge.

tions, if that set includes more than one possibility. The answer to this question would depend on, among other things, whether a concensus of the constituent groups of a polity is necessary to establish a constitution, or whether either one of the constituent groups or an outsider can impose a constitution. Other authors, such as Daron Acemoglu and James Robinson (2001) and Adam Przeworski (1991, 2001), who have analyzed the viability of constitutions have looked at civil conflict as a mechanism for switching between democratic and nondemocratic constitutions. In other related literature Avinash Dixit, Gene Grossman, and Faruk Gul (2000), who generalize the seminal work of Alberto Alesina (1988), pose as alternatives a constitution that specifies limits on the prerogatives of the party in power and a constitution without such limits. These authors implicitly assume that both of these constitutions would be viable. Importantly, none of these contributions view a constitution and civil conflict to be alternative ongoing methods for resolving distributional disputes, as in the present paper.

${ }^{3}$ Although the present paper focuses on distributional disputes between social classes, the analysis can easily be extended to apply to any instance of recurring disputes between constituent groups of a polity. See Herschel Grossman (2003).

${ }^{4}$ The analysis treats the social classes as unitary agents, thereby abstracting from the processes by which the members of a social class collectively choose their actions and enforce these choices. 
Because this simple constitution places no limits on the prerogatives of the winner, if $L$ were to win a constitutional contest, then $L$ would set $s$ equal to one, whereas, if $W$ were to win a constitutional contest, then $W$ would set $s$ equal to zero. Thus, under this simple constitution the expected value of $s$, denoted by $\bar{s}$, equals $p$.

To contrast this simple constitution with a civil conflict, normalize the costs of a constitutional contest to zero, and let the positive numbers, $c_{\mathrm{L}}$ and $c_{\mathrm{W}}$, which are calibrated in units of income, denote the expected incremental costs of a civil conflict to the respective social classes. These incremental costs include the allocation of scarce resources to arming and to other conflictual activities and, if conflict escalates beyond the threat of the use of force, the possible destruction of scarce resources and even loss of life. Assume that $c_{\mathrm{L}}$ and $c_{\mathrm{W}}$ are exogenous and common knowledge. ${ }^{5}$

Finally, let $L$ have probability $q$, and let $W$ have probability $1-q$, of winning a civil conflict. Assume that these probabilities are exogenous and also common knowledge. ${ }^{6}$ Assume also that the social class that wins a civil conflict, like the winner of a constitutional contest under this simple constitution, would take all of the appropriable economic rents for itself.

\footnotetext{
${ }^{5}$ For simplicity the model assumes that $c_{\mathrm{L}}$ and $c_{\mathrm{W}}$ do not depend on $y$. Assuming instead that $c_{\mathrm{L}}$ and $c_{\mathrm{W}}$ increase with $y$ would not change the qualitative implications of the model as long as the ratios, $c_{\mathrm{L}} / y$ and $c_{\mathrm{W}} / y$, are not constants. In a complementary analysis Joan Estaban and Debraj Ray (2001) focus on the resource costs of constitutional contests. An alternative way to make the expected cost of civil conflict larger than the expected cost of a constitutional contest would be to assume that the social classes are risk averse and that under a constitution, but not with civil conflict, the social classes can implement supplementary understandings that decrease the variance of $s$. Alesina (1988) and Dixit, Grossman, and Gul (2000) explore the possibility of collusion by political actors to decrease risk.

${ }^{6}$ An interesting extension of the model would be to endogenize $q$, as in papers like Dmitriy Gershenson and Herschel Grossman (2000) and Herschel Grossman (1999) that focus on the decision to allocate resources to civil conflict. Another interesting extension would be to allow $q$ to be a state variable whose current value depends on past outcomes of constitutional contests and civil conflicts.
} 


\section{A bide or A brogate?}

Suppose that a polity establishes a simple constitution and that one of the social classes wins a constitutional contest. Now the other social class, the loser of the constitutional contest, has to make a choice. The loser can decide to abide by the constitution, thereby allowing the winner to exercise its constitutional prerogative to set $s$. Or, the loser can abrogate the constitution, attempt to prevent the winner from exercising its constitutional prerogative, and thereby initiate a civil conflict. (If the constitutional contest was an election, then we commonly say that the loser can either accept or not accept the results of the election.) A simple constitution is self enforcing if the loser of a constitutional contest, whether that is $L$ or $W$, will choose to abide by the constitution if it can expect future losers of constitutional contests to abide by the constitution.

Assume that the losing social class will abide by the constitution if and only if the present value of its expected income from abiding by the constitution would be at least as large as the present value of its expected income from abrogating the constitution. To determine these present values, assume that, as long as both social classes abide by the constitution, they can settle future distributional disputes between them constitutionally, but that, if either social class were to abrogate the constitution, then they would be left to settle future distributional disputes by civil conflict. ${ }^{7}$

Given these assumptions, the social class, either $L$ or $W$, that has lost a constitutional contest abides by the constitution if and only if $\bar{s}$ satisfies both of the following conditions:

$$
\begin{aligned}
\frac{\rho}{1-\rho} \bar{s} y & \geq \frac{1}{1-\rho}\left(q y-c_{\mathrm{L}}\right) . \\
\frac{\rho}{1-\rho}(1-\bar{s}) y & \geq \frac{1}{1-\rho}\left[(1-q) y-c_{\mathrm{W}}\right] .
\end{aligned}
$$

\footnotetext{
${ }^{7}$ If the consequences of abrogation were less drastic - for example, if a refusal to abide by the constitution in resolving the distributional dispute did not preclude with certainty the possibility of resolving distributional disputes constitutionally in the future - then the configurations of exogenous parameters under which it is possible to design a self-enforcing constitution would be more restricted.
} 
The parameter $\rho, \rho \in[0,1)$, in conditions (1) and (2) is an exogenous discount factor. The larger is $\rho$ the more concern that the social classes have for the future consequences of their current actions.

The LHS of condition (1) is the present value of the expected income of $L$, if it has lost a constitutional contest, from abiding by the constitution, given that $L$ expects that losers of future constitutional contests will abide by the constitution. Because $W$ sets $s$ equal to zero, the expected income of $L$ from abiding by the constitution is equal to zero plus the present value of expecting to get $\bar{s} y$ in future distributional disputes. The RHS of condition (1) is the present value of the expected income of $L$ from abrogating the constitution and settling the current distributional dispute and future distributional disputes by civil conflict. With civil conflict $L$ expects to get $y$ with probability $q$ and to get zero with probability $1-q$, and to incur the $\operatorname{cost} c_{\mathrm{L}}$ in each recurrence of the dispute. Condition (2) applies analogously to $W$. Conditions (1) and (2) assume that $y, q, c_{\mathrm{L}}, c_{\mathrm{W}}, \rho$, and $\bar{s}$ are expected to remain unchanged in the future.

Taken together conditions (1) and (2) imply the following proposition, which is derived in the mathematical appendix:

If and only if the configuration of exogenous parameters satisfies

$$
\boldsymbol{m a x}\left\{\boldsymbol{q}-\frac{\boldsymbol{c}_{\mathrm{L}}}{\boldsymbol{y}}, \quad 1-\boldsymbol{q}-\frac{\boldsymbol{c}_{\mathrm{W}}}{\boldsymbol{y}}, \quad 1-\frac{\boldsymbol{c}_{\mathrm{L}}}{\boldsymbol{y}}-\frac{\boldsymbol{c}_{\mathrm{W}}}{\boldsymbol{y}}\right\} \leq \boldsymbol{\rho},
$$

then the set of values of $\bar{s}$ that satisfy both condition (1) and condition (2) is not empty. Hence, if and only if the configuration of exogenous parameters satisfies condition (3), then it is possible to design a simple self-enforcing constitution that, regardless of which social class wins a constitutional contest, settles distributional disputes between the social classes without civil conflict.

Condition (3) implies that the following properties of the exogenous parameters would 
help to make constitutional resolution of recurring distributional disputes a viable alternative to civil conflict:

- Neither the probability $q$ nor the probability $1-q$ is too large. This property means that neither social class has a big advantage in civil conflict.

- The ratios, $c_{\mathrm{L}} / y$ and $c_{\mathrm{W}} / y$, which calibrate the expected incremental costs of civil conflict relative to aggregate appropriable economic rents, are large.

- The discount factor, $\rho$, is large. ${ }^{8}$

The observation that large values of $c_{\mathrm{L}} / y$ and $c_{\mathrm{W}} / y$ help to make a self-enforcing constitution possible is especially interesting because it conveys both good news and bad news. The good news is that, given aggregate appropriable economic rents, if civil conflicts would have sufficiently large incremental costs, and if these large incremental costs are anticipated - that is, if $c_{\mathrm{L}}$ and $c_{\mathrm{W}}$ are sufficiently large - then civil conflict is avoidable. The bad news is that, given the expected incremental costs of civil conflict, if aggregate appropriable economic rents are sufficiently large, then civil conflict is unavoidable.

\section{Limits on the Prerogatives of the $\mathrm{W}$ inner}

Suppose that the configuration of exogenous parameters is such that a simple constitution would not be viable. Is it possible that with the same configuration of exogenous parameters a more complex constitution that includes limits on the prerogatives of winners of constitutional contests could be viable?

Let the limits on the prerogatives of the winner of a constitutional contest under such a complex constitution be that the winner will not choose $s$ to be either larger than $s_{\mathrm{L}}$ or smaller than $s_{\mathrm{W}}$. If $s_{\mathrm{L}}$ is smaller than one, then this limit is a binding constraint on $L$. If $s_{\mathrm{W}}$ is positive, then this limit is a binding constraint on $W$. Under this complex constitution

\footnotetext{
${ }^{8} \mathrm{It}$ is worth noting that condition (3) can be satisfied only if either $c_{\mathrm{L}} / y$ or $c_{\mathrm{W}} / y$ is positive, but that, if $c_{\mathrm{L}} / y$ and $c_{\mathrm{W}} / y$ are sufficiently large, then condition (3) can be satisfied even if $\rho$ equals zero.
} 
the expected value of $s, \bar{s}$, equals $p s_{\mathrm{L}}+(1-p) s_{\mathrm{W}}$. The triple, $T$, where $T=\left\{\bar{s}, s_{\mathrm{L}}, s_{\mathrm{W}}\right\}$, describes this complex constitution.

Under what configurations of exogenous parameters is it possible to design a complex constitution that is self enforcing? Suppose that a polity establishes a complex constitution described by a triple, $T$, and that a constitutional contest takes place. Given that this complex constitution imposes a binding constraint on the prerogatives of the winner, both the loser and the winner have to decide whether to abide by the constitution or to abrogate the constitution. A complex constitution is self enforcing (1) if the loser of a constitutional contest will choose to abide by the constitution if it can expect that the winner will abide by the constitution and that future losers and winners of constitutional contests will abide by the constitution and (2) if the winner of the constitutional contest will choose to abide by the constitution if the loser is abiding by the constitution and if the winner can expect that future losers and winners of constitutional contests will abide by the constitution.

Suppose that $L$ is the winner of the constitutional contest. Consider the choice that $W$ faces. Having lost the constitutional contest, if $W$ expects that $L$ will abide by the constitution and that future losers and winners of constitutional contests will abide by the constitution, then $W$ abides by the constitution if and only if $s_{\mathrm{L}}$ and $\bar{s}$ are small enough to satisfy the following condition:

$$
\left(1-s_{\mathrm{L}}\right) y+\frac{\rho}{1-\rho}(1-\bar{s}) y \geq \frac{1}{1-\rho}\left[(1-q) y-c_{\mathrm{W}}\right] .
$$

The LHS of condition (4) is the present value of the expected income of $W$ from abiding by the constitution, given that $W$ expects that $L$ will abide by the constitution and that both losers and winners of future constitutional contests will abide by the constitution. Because in abiding by the constitution $L$ will set $s$ equal to $s_{\mathrm{L}}$, the expected income of $W$ from abiding by the constitution is equal to $\left(1-s_{\mathrm{L}}\right)$ y plus the present value of expecting to get $(1-\bar{s}) y$ in future distributional disputes. A comparison of the LHS of condition (4) with the LHS of condition (2) shows how a constraint on $L$, in the form of $s_{\mathrm{L}}$ smaller than 
one, makes it more attractive for $W$ to abide by the constitution. The RHS of condition (4), which is identical to the RHS of condition (2), is the present value of the expected income of $W$ from abrogating the constitution. Condition (4) assumes that $W$ expects $y, q, c_{W}$, $\rho$, and $T$ to remain unchanged in the future. ${ }^{9}$

Now consider $L$, the winner of the constitutional contest. If $W$ is abiding by the constitution, then $L$ can exercise its constitutional prerogative to choose $s$. In choosing $s$, either $L$ can abide by the limitation that it will not set $s$ larger than $s_{\mathrm{L}}$ or $L$ can behave opportunistically, disregard this limit, set $s$ larger than $s_{\mathrm{L}}$, and thereby abrogate the constitution.

Assume that $L$ will abide by the limit on its constitutional prerogative only if the present value of its expected income from setting $s$ equal to $s_{\mathrm{L}}$ would be at least as large as the present value of its expected income from setting $s$ equal to one, which is its best opportunistic choice. Accordingly, if $W$ is abiding by the constitution, and if $L$ expects that future losers and winners of constitutional contests will abide by the constitution, then $L$ abides by the constitution if and only if $s_{\mathrm{L}}$ and $\bar{s}$ are large enough to satisfy the following condition:

$$
s_{\mathrm{L}} y+\frac{\rho}{1-\rho} \bar{s} y \geq y+\frac{\rho}{1-\rho}\left(q y-c_{\mathrm{L}}\right) .
$$

The LHS of condition (5) is the present value of the expected income of $L$ from abiding by the constitution given that $W$ is abiding by the constitution and that $L$ expects that future losers and winners of constitutional contests will abide by the constitution. Because in abiding by the constitution $L$ sets $s$ equal to $s_{\mathrm{L}}$, the expected income of $L$ from abiding by the constitution is equal to $s_{\mathrm{L}} y$ plus the present value of expecting to get $\bar{s} y$ in future distributional disputes. The RHS of condition (5) is the present value of the expected income of $L$ from being opportunistic by setting $s$ equal to one and, thereby, causing future distributional disputes to result in civil conflict. Condition (5) assumes that $L$ expects $y$,

\footnotetext{
${ }^{9}$ We might suppose that, because $L$ prefers $s$ to be larger, if condition (4) is satisfied, then it is satisfied as an equality. The conclusions derived below do not depend on whether condition (4) is satisfied as an inequality or as an equality.
} 
$\rho, q, c_{\mathrm{L}}$, and $T$ to remain unchanged in the future.

Condition (4) requires that the sum, $s_{\mathrm{L}}+\rho \bar{s} /(1-\rho)$, which is the present value of current and expected future realizations of $s$, conditional on $L$ winning a constitutional contest under a complex constitution, is not too large, whereas condition (5) requires that this sum is not too small. The analogous conditions that apply if $W$ has won a constitutional contest require that the sum, $s_{\mathrm{W}}+\rho \bar{s} /(1-\rho)$, is neither too large not too small. These properties imply the following proposition:

The specification of a complex constitution that provides a viable alternative to civil conflict must be such that the constitution does not produce on average a distribution of appropriable economic rents that is too favorable to one social class or the other and that which social class wins a constitutional contest does not matter too much for the current distribution of appropriable economic rents.

In addition conditions (4) and (5) and the analogous conditions that apply if $W$ has won a constitutional contest taken together imply the following proposition, which is derived in the mathematical appendix:

If and only if the configuration of exogenous parameters satisfies

$$
\boldsymbol{m a x}\left\{\frac{\boldsymbol{q}-\boldsymbol{c}_{\mathrm{L}} / \boldsymbol{y}}{\boldsymbol{q}+\boldsymbol{c}_{\mathrm{W}} / \boldsymbol{y}}, \frac{1-\boldsymbol{q}-\boldsymbol{c}_{\mathrm{W}} / \boldsymbol{y}}{1-\boldsymbol{q}+\boldsymbol{c}_{\mathrm{L}} / \boldsymbol{y}}, \frac{1-c_{\mathrm{L}} / \boldsymbol{y}-c_{\mathrm{W}} / \boldsymbol{y}}{1+c_{\mathrm{L}} / \boldsymbol{y}+c_{\mathrm{W}} / \boldsymbol{y}}\right\} \leq \rho,
$$

then the set of triples, $\boldsymbol{T}$, that satisfy condition (4), condition (5), and the analogous conditions that apply if $\boldsymbol{W}$ has won a constitutional contest is not empty. Hence, if and only if the configuration of exogenous parameters satisfies condition (6), then it is possible to design a complex self-enforcing constitution that, regardless of which social class wins a constitutional contest, can settle distributional disputes between the social classes without civil conflict. 
Condition (6) has the same implications as condition (3) regarding the properties of the exogenous parameters that make constitutional resolution of a distributional disputes a viable alternative to civil conflict - namely, neither $q$ nor $1-q$ is too large, $c_{\mathrm{L}} / y$ and $c_{\mathrm{W}} / y$ are large, and $\rho$ is large. More interestingly, comparing condition (6) with condition (3), we obtain the following result, which is derived in the mathematical appendix:

If the discount factor, $\rho$, is positive, then the set of configurations of exogenous parameters that satisfy condition (3) is a proper subset of set of configurations of exogenous parameters that satisfy condition (6). Hence, if $\rho$ is positive, then, even if it is not possible to design a simple self-enforcing constitution, it can be possible to design a selfenforcing constitution that includes binding limits of the prerogatives of the social class that wins a constitutional contest.

If the configuration of exogenous parameters is such that, even though it is not possible to design a simple self-enforcing constitution, it is possible to design a complex self-enforcing constitution, then, given this configuration of exogenous parameters, it is possible by limiting the prerogatives of winners of constitutional contests to induce losers abide by the constitution without causing winners to abrogate the constitution.

\section{Summary}

Constitutional resolution of distributional disputes between constituent groups of a polity avoids the incremental costs of civil conflict. But, the political process prescribed by a constitution provides a viable alternative to civil conflict only if the constitution is self enforcing. The analysis in this paper revealed that the following characteristics of the configuration of exogenous parameters help to make it possible to design a self-enforcing constitution:

- Neither class has a big advantage in civil conflict. 
- The expected incremental costs of civil conflict are large relative to aggregate appropriable economic rents.

- Both social classes are greatly concerned about the future consequences of their current actions.

Alternatively, either a big advantage in civil conflict for one of the social classes, or expectations that the incremental costs of civil conflict would be small relative to the aggregate appropriable economic rents, or little concern for the future consequences of current actions can preclude the designing of a self-enforcing constitution.

The analysis also has the following important implication:

- If it is possible to design a self-enforcing constitution that can settle distributional disputes between social classes, then such a constitution can require limitations on the prerogatives of winners of constitutional contests such that on average the distribution of appropriable economic rents under the constitution is not too favorable to one social class or the other and such that the outcome of a constitutional contest does not matter too much for the current distribution of economic rents. 


\section{R eferences}

Acemoglu, Daron and Robinson, James. "A Theory of Political Transitions." American E conomic Review, 97(1), September 2001, 938-963.

Alesina, Alberto. "Credibility and Policy Convergence in a Two-social class System with Rational Voters." American Economic Review, 78(1), September 1988, 796-805.

Dixit, Avinash, Grossman, Gene M., and Gul, Faruk. "The Dynamics of Political Compromise." J ournal of Political E conomy, 108(3), June 2000, 531-568.

Estaban, Joan and Ray, Debraj. "Social Decision Rules Are Not Immune to Conflict." E conomics of Governance, 2(1), 2001, 59-67.

Gershenson, Dmitriy and Grossman, Herschel I. "Civil Conflict: Ended or Never Ending?" J ournal of Conflict Resolution, 44(3), December 2000, 807-821.

Grossman, Herschel I. "Kleptocracy and Revolutions." Oxford Economic Papers, 51, April 1999, 267-283.

Grossman, Herschel I. "Constitution or Conflict?" unpublished, May 2003.

Przeworski, Adam. Democracy and the Market. New York: Cambridge University Press, 1991.

Przeworski, Adam. "Democracy as an Equilibrium." unpublished, March 2001. 


\section{M athematical A ppendix}

Derivation of Condition (3):

Condition (1) is satisfied if and only if $\bar{s}$ is sufficiently large that

$$
\bar{s} \geq \frac{q-c_{\mathrm{L}} / y}{\rho} .
$$

Condition (2) is satisfied if and only if $\bar{s}$ is sufficiently small that

$$
\bar{s} \leq 1-\frac{1-q-c_{\mathrm{W}} / y}{\rho} .
$$

Conditions $(i)$ and $(i i)$ have the following implications:

(3.1) If and only if the RHS of condition $(i)$ is not larger than one, then the set of values of $\bar{s}, \bar{s} \in[0,1]$, that satisfy condition $(i)$ is not empty.

(3.2) If and only if the RHS of condition (ii) is not negative, then the set of values of $\bar{s}$, $\bar{s} \in[0,1]$, that satisfy condition (ii) is not empty.

(3.3) If and only if the RHS of condition (ii) is not smaller than the RHS of condition (i), then the union of the set of values of $\bar{s}$ that satisfy condition $(i)$ and the set of values of $\bar{s}$ that satisfy condition (ii) is not empty.

If and only if condition (3) obtains, where

$$
\max \left\{q-\frac{c_{\mathrm{L}}}{y}, \quad 1-q-\frac{c_{\mathrm{W}}}{y}, \quad 1-\frac{c_{\mathrm{L}}}{y}-\frac{c_{\mathrm{W}}}{y}\right\} \leq \rho,
$$

then conditions (3.1), (3.2), and (3.3) obtain.

\section{Derivation of Condition (6):}

Both condition (4) and condition (5) are satisfied if and only if the triple, T, satisfies

$$
\frac{1}{1-\rho}\left(q+c_{\mathrm{W}} / y\right) \geq s_{\mathrm{L}}+\frac{\rho}{1-\rho} \bar{s} \geq 1+\frac{\rho}{1-\rho}\left(q-c_{\mathrm{L}} / y\right) .
$$


The analogous condition that applies if $W$ has won a constitutional contest is satisfied if and only if $T$ satisfies

$$
\frac{\rho}{1-\rho}\left(q+c_{\mathrm{W}} / y\right) \geq s_{\mathrm{W}}+\frac{\rho}{1-\rho} \bar{s} \geq \frac{1}{1-\rho}\left(q-c_{\mathrm{L}} / y\right) .
$$

Conditions (iii) and (iv) have the following implications:

(6.1) If and only if the LHS of condition ( $i i i)$ is not smaller than the RHS of condition (iii), then the set of values of $s_{\mathrm{L}}$ that satisfy condition (iii) is not empty.

(6.2) If and only if the LHS of condition (iv) is not smaller than the RHS of condition (iv), then the set of values of $s_{\mathrm{W}}$ that satisfy condition $(i v)$ is not empty.

(6.3) If and only if the difference between the LHS of condition (iii) and the RHS of condition $(i v)$ is not smaller than the difference between the RHS of condition (iii) and the LHS of condition $(i v)$, then the set of values of $\bar{s}$ that satisfy both condition (iii) and condition (iv) is not empty.

If and only if condition (6) obtains, where

$$
\max \left\{\frac{q-c_{\mathrm{L}} / y}{q+c_{\mathrm{W}} / y}, \frac{1-q-c_{\mathrm{W}} / y}{1-q+c_{\mathrm{L}} / y}, \frac{1-c_{\mathrm{L}} / y-c_{\mathrm{W}} / y}{1+c_{\mathrm{L}} / y+c_{\mathrm{W}} / y}\right\} \leq \rho,
$$

then conditions (6.1), (6.2), and (6.3) obtain.

\section{Derivation of the result that the set of configurations of exogenous parameters that satisfy condition (3) is a proper subset of the set of configurations of exoge- nous parameters that satisfy condition (6):}

Define $Y \equiv q-c_{\mathrm{L}} / y$, and define $Z \equiv 1-q-c_{\mathrm{W}} / y$.

Using these definitions, we can rewrite condition (3) as

$$
\max \{Y, Z, \quad Y+Z\} \leq \rho,
$$


and we can rewrite condition (6) as

$$
\max \left\{\frac{Y}{1-Z}, \frac{Z}{1-Y}, \frac{Y+Z}{2-Y-Z}\right\} \leq \rho
$$

Also, note that $\max \{Y, Z, Y+Z\} \leq 1$.

To compare condition (3) and condition (6) we have to consider four cases:

1. If both $Y \leq 0$ and $Z \leq 0$, then the configuration of exogenous parameters satisfies both condition (3) and condition (6).

2. If both $Y>0$ and $Z>0$, then $\max \{Y, Z, Y+Z\}=Y+Z$. In addition, with $Y>0$ and $Z>0$, and with $\max \{Y, Z, Y+Z\} \leq 1$, we have

$$
Y+Z>\max \left\{\frac{Y}{1-Z}, \frac{Z}{1-Y}, \frac{Y+Z}{2-Y-Z}\right\}
$$

3. If $Y \leq 0$ and $Z>0$, then $\max \{Y, Z, Y+Z\}=Z$. In addition, with $Y \leq 0$ and $Z>0$, and with $\max \{Y, Z, Y+Z\} \leq 1$, we have

$$
Z>\max \left\{\frac{Y}{1-Z}, \frac{Z}{1-Y}, \frac{Y+Z}{2-Y-Z}\right\}
$$

4. If $Y>0$ and $Z \leq 0$, then $\max \{Y, Z, Y+Z\}=Y$. In addition, with $Y>0$ and $Z \leq 0$, and with $\max \{Y, Z, Y+Z\} \leq 1$, we have

$$
Y>\max \left\{\frac{Y}{1-Z}, \frac{Z}{1-Y}, \frac{Y+Z}{2-Y-Z}\right\}
$$

In the latter three cases, $\max \{Y /(1-Z), Z /(1-Y),(Y+Z) /(2-Y-Z)\}$ is positive but smaller than $\max \{Y, Z, Y+Z\}$. Thus, in these cases, if $\rho$ is positive, then the configuration of exogenous parameters can satisfy condition (6) even if it does not satisfy condition (3). 